\title{
Isolated Developmental Venous Anomaly of the Pons with Transpontine Drainage: Case Report
}

\author{
Y. T. Yamgoue Tchameni - M. Messerer · J. B. Zerlauth • \\ M. Levivier · R. T. Daniel
}

Received: 10 December 2012 / Accepted: 23 January 2013 / Published online: 9 February 2013

C Springer-Verlag Berlin Heidelberg 2013

\section{Introduction}

Initially known as venous angioma, Developmental Venous Anomaly (DVA) is a persistent variant of fetal brain venous drainage $[1,2]$. Unlike cerebellar DVA with or without brainstem extension, isolated pontine DVA is a rare condition [3, 4]; and as per our knowledge, its presentation with exclusive transpontine drainage has never been described before. The authors present the case of an isolated pontine DVA with a selective transpontine drainage discovered incidentally; the clinical presentation, the radiological findings, and the management are discussed.

\section{Case Report}

A 77-year-old woman presented to the emergency unit with a transient constellation of nonspecific symptoms, and no clearly defined neurological symptoms or signs. The brain CT scan and MRI sequences: T1 turbo spin echo (TSE) with and without injection of gadolinium (Gd), T2 TSE, T2 gradient echo as well as MRI diffusion images excluded an

R. T. Daniel, MD ( $\triangle)$

Neurosurgeon. Vascular neurosurgery, Skull Base Surgery,

Pediatric Neurosurgery. Lausanne University Hospital,

Switzerland

e-mail: Roy.Daniel@chuv.ch

Y. T. Yamgoue Tchameni, MD · M. Messerer, MD ·

M. Levivier, MD, $\mathrm{PhD}$

Service of Neurosurgery, Department of Clinical Neurosciences, Lausanne University Hospital, Lausanne, Switzerland

e-mail: yamgoue.yves@gmail.com

J. B. Zerlauth, MD

Unit of Neuroradiology, Department of Radiology,

Lausanne University Hospital, Lausanne, Switzerland ischemic or hemorrhagic lesion of the brain, but revealed an incidental pontine vascular lesion. CT scan of the brain (Fig. 1a, b) revealed a diffuse enhancement of the center and right side of the pons; with an adjacent vascular-like enhancement located in the right pontine tegmentum. Sagittal T1 TSE (Fig. 2a) revealed a hypointense lesion in the pontine tegmentum; this latter showed a vascular-like enhancement (Fig. 2b). Axial T1 TSE Gd images showed a vascular-like enhancement presenting radicular divisions in the deep pontine tegmentum having a caput medusae appearance (Fig. 3a), without extension to the cerebellum or the fourth ventricle. This vascular enhancement passes through the right pontine tegmentum, and exits in the right pontocerebellar cistern (Fig. 3b). Axial T2 TSE images (Fig. 4a, b) showed a linear hypointense signal following the pathway of the right pontocerebellar cistern, the right pontine tegmentum, and directing towards the anterior part of the fourth ventricle's floor (arrows in Fig. 4a, b). Gradient echo T2 images (Fig. 5) clearly showed a hypointense vascular-like signal in the right pontine tegmentum, with deep hypointense radicular divisions. The radiologic presentation was consistent with an isolated DVA of the pons with a transpontine drainage, without associated bleeding or stenosis of the main collector vein. The laboratory exams revealed a moderate hyponatremia, which was corrected with intravenous fluids. A conservative management was adopted with complete relief of symptoms. The patient was discharged two days after admission.

\section{Discussion}

DVA is a persistent variant of fetal brain venous drainage $[1,2]$. This is thought to be due to an arrest of formation or thrombosis of the developing venous drainage system, 

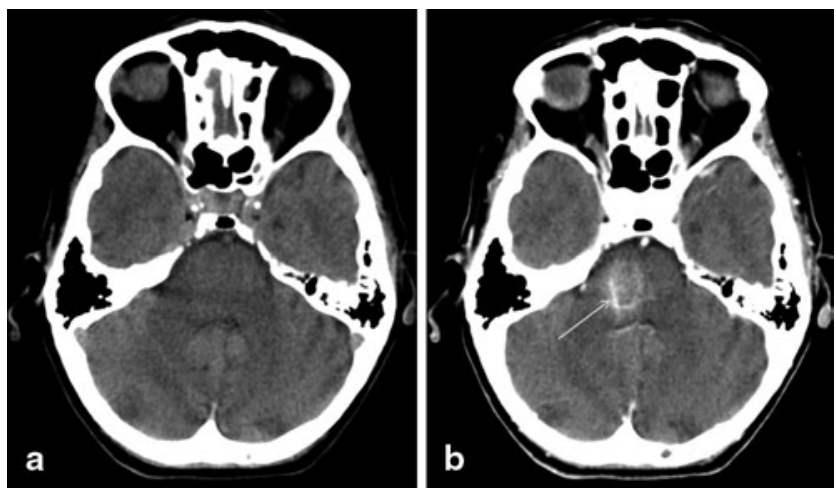

Fig. 1 a Axial noncontrast brain CT scan. b Axial contrast brain CT scan. There is a vascular-like enhancement located in the right pontine tegmentum, extending toward the floor of the fourth ventricle (arrow in b); this represents the DVA drainage. Around this vascularlike enhancement, and mostly at its left, there is a diffuse contrast enhancement without enlargement of the pons, nor mass effect on the peripheral structures; representing a site of hyperemia due to the terminal divisions of the DVA
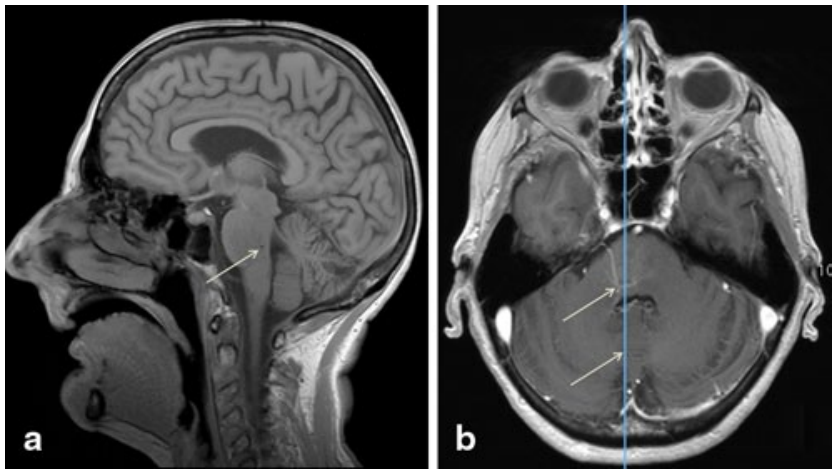

Fig. 2 Sagittal T1 TSE image (a) and Axial T1 TSE Gd image (b). The reference line in blue (lower arrow in figure b) is passing through drainage vein (upper arrow in figure b). The drainage vein appears as a hypointense structure on noncontrast images (a), and shows a vascular-like contrast enhancement with deep terminal division branches (b)
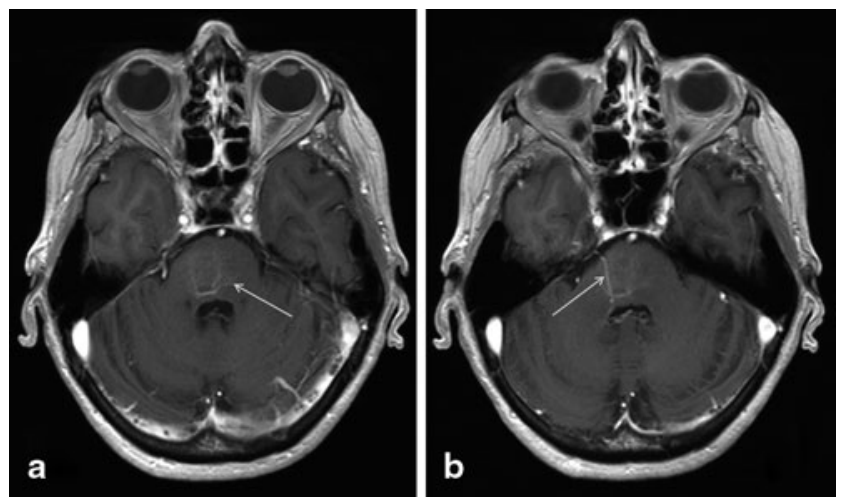

Fig. 3 Axial T1 TSE Gd images (a and b). This illustrates a vascularlike enhancement, with deep radicular divisions in the pontine tegmentum (arrow in a) corresponding to the radicular branches of the DVA. In b (arrow), we can clearly identify a vascular enhancement, passing through the right pontine tegmentum, and exiting the pons at the level or the right pontocerebellar cistern. This represents the drainage vein of the DVA. There is no extension toward the cerebellar regions or to the fourth ventricle

Springer
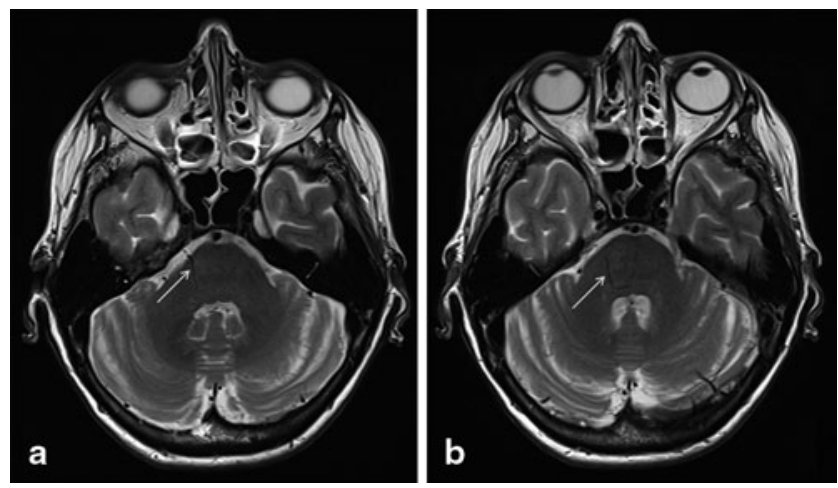

Fig. 4 Axial T2 TSE images (a and b). This shows a linear hypointense structure exiting the pons through the right ponto-cerebellar angle, and located essentially in the right pontine tegmentum, corresponding to the drainage vein of the DVA (arrows). There is no extension towards the cerebellar regions or to the fourth ventricle

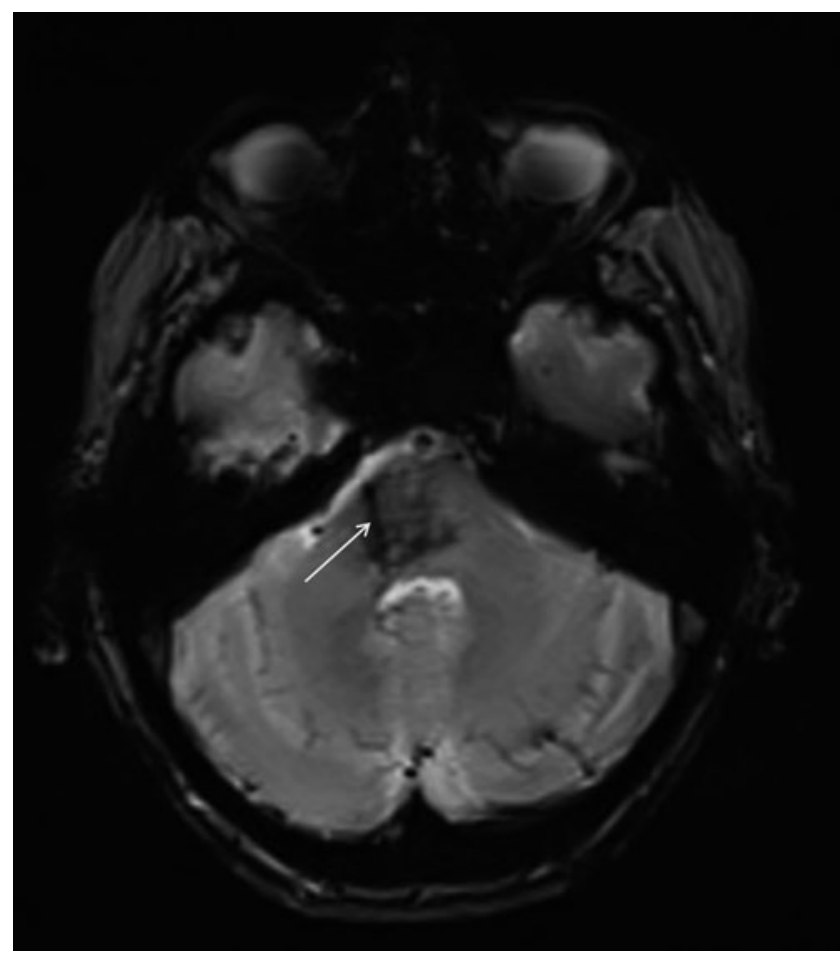

Fig. 5 Axial gradient echo T2 image (T2*). This illustrates a linear shape hypointensity passing through the right pontine tegmentum, with an exit point in the right ponto-cerebellar cistern. This corresponds to the DVA collecting vein. This latter shows hypointense divisions in the deep pontine tegmentum representing the radicular branches of the DVA. There is no diffuse hypointensity, which excludes an associated telangiectasia

which leads to a secondary dilatation of peripheral venules, with classic aspect of caput medusae [5-7]. DVA is the most frequent cerebrovascular malformation [8]. Its incidence varies between $0.48 \%[9,10]$, up to $4.05 \%$ in some autopsy series [11]. DVA can appear as an isolated finding or can be in association with other malformations such as cavernous angioma [12-21] or capillary telangiectasia 
$[22,23]$. Among nonarterial vascular malformations, the most frequent association has been described between DVA and cavernous malformations [24, 25]. Recently, some authors have reported cases or malformations appearing in a triad composed of capillary telangiectasia, cavernous angioma, and DVA $[5,25,26]$. In our report, the DVA was observed as an isolated vascular anomaly. This anomaly was located within the pons, with an exclusive transpontine drainage (Fig. 3a, b). According to the literature, in one-third of cases, DVA are located in the posterior fossa $[10,27,28]$, predominantly in the cerebellum with a prevalence of $14-36 \%[4,29]$. Around $3-8.7 \%$ of DVA $[4,29]$ are located in the brainstem; only a $1.5 \%$ prevalence is reported of pontine location [29]. As per our knowledge, a case of isolated exclusive pontine DVA with selective transpontine drainage has never been reported. Four reported cases of exclusive pontine DVA with selective transpontine drainage were associated with other vascular malformations $[24,25,30,31]$. There is one reported case of isolated exclusive pontine DVA, with collector vein draining through the fourth ventricle, into the vein of Galen [32].

The radiological findings of DVA are well established $[1,9]$. Independent of the imaging modality, the diagnosis relies on demonstrating a typical caput medusae draining into a collecting vein. The gold standard method remains the digital subtraction angiography, but in most cases CT and MRI allow the diagnosis of such lesions; the last one being superior to demonstrate associated parenchymal abnormalities. Noncontrast CT reveals the collecting vein as isodense or slightly hyperdense (if patent) or markedly hyperdense (if thrombosed). Noncontrast T2 and T1 weighted MRI may reveal flow voids and phase-shift artifact due to the collecting veins and the larger venous radicles of the caput medusae. After contrast administration, the caput medusae and the collecting veins enhance both on CT and T1 weighted MRI. In case of a pontine location, as in our report, capillary telangiectasia may be evoked [35-37]. It may be difficult to differentiate between the two lesions. It should specifically sought for using hemosiderin or deoxyhemoglobin sensitive sequences such as gradient echo T2 weighted images or susceptibility weighted images (SWI) [38]. The radiological features of telangiectasias on MRI imaging are hyperintensity on T2 SE (or T2 TSE), which can often be absent as well $[36,37]$. Diffuse hypointensity on gradient echo T2 weighted images, on the other hand, is more specific [36]. In our report, these two specific MRI observations for capillary telangiectasia were absent (Figs. 4a, b, and 5). Moreover, the different MRI sequences showed a large pontine drainage vein (Figs. 3b, 4b, and 5), with radicular branches in the deep pontine tegmentum (Figs. $3 \mathrm{a}$ and 5). This remains consistent with a DVA of the pons.

DVA classically remains asymptomatic, and is frequently encountered as an incidental radiological finding [8] on cerebral images performed for unrelated symptomatology. The clinical significance of DVA and its management remain controversial [8,33]. The most frequent related symptoms reported in hospital-based clinical studies are headaches $(50.8 \%)$, focal neurologic deficits $(39.7 \%)$, and seizures (30.2\%) [34]. Given the benign nature of DVA, their causality effect toward these symptoms is uncertain. Garner et al. [4], in their studies on 100 patients with DVA, described the possible causality relation of neurological symptoms to a DVA: headaches in $4 / 36$, seizures in $5 / 23$, and focal neurological deficit in $8 / 41$. The hemorrhagic risk of DVA is negligible [12]. It varies from 0.22 to $0.68 \%$ per year [12, 29]. Following recent studies, supratentorial and posterior fossa DVA carry the same hemorrhagic risk [29, 34]. In hemorrhagic cases, the DVA is usually associated with a related mature or immature cavernous malformation, often found in the venous angioma's radicular branches, responsible for the bleeding [25]. The hypothesis for bleeding in isolated cases of DVA is possibly due to stenosis or thrombosis of the collector vein $[8,25]$ with consecutive intracranial venous hypertension within the radicular veins of the DVA leading to microbleeds.

In our report, there was neither infarct nor bleeding in the brainstem. Our patient presented with a transient constellation of symptoms that could not be ascribed to the pontine location of this DVA. We effectively considered this diagnostic as an incidental finding.

DVA are known to be anatomic variations draining normal brain (or brainstem) parenchyma $[2,5]$. Hence, the surgical resection of these lesions or radiosurgery on DVA is contraindicated [39]. Resection of DVA carries the risk of hemorrhage, venous infarction, or extensive edema of normal brain, brainstem, or cerebellar tissue [28, 40, 41]. The only possible indications for surgery in cases of DVA are the rare instances when they present with an extensive intraparenchymal hematoma with mass effect [42-44].

\section{Conclusion}

The authors describe the first reported case of isolated pontine DVA with exclusively transpontine drainage, discovered incidentally. In the absence of an ischemic or hemorrhagic presentation, the clinical significance of DVA remains uncertain. Hence no surgical treatment is warranted for these vascular lesions.

Conflict of Interest The authors attest that there is no conflict of interest for the submission and publication of the present case report. 


\section{References}

1. Truwit CL. Venous angioma of the brain: history, significance, and imaging findings. Am J Roentgenol. 1992;159(6):1299-307.

2. Lasjaunias P, Burrows P, Planet C. Developmental venous anomalies (DVA): the so-called venous angioma. Neurosurg Rev. 1986;9(3):233-42.

3. Kuker W, Mull M, Thron A. Developmental venous anomalies of the posterior fossa with transpontine drainage: report of 3 cases. Eur Radiol. 1997;7(6):913-7.

4. Garner TB, Del Curling O Jr, Kelly DL Jr, Laster DW. The natural history of intracranial venous angiomas. J Neurosurg. 1991;75(5):715-22. doi:10.3171/jns.1991.75.5.0715.

5. Clatterbuck RE, Elmaci I, Rigamonti D. The juxtaposition of a capillary telangiectasia, cavernous malformation, and developmental venous anomaly in the brainstem of a single patient: case report. Neurosurgery. 2001;49(5):1246-50.

6. Saito Y, Kobayashi N. Cerebral venous angiomas: clinical evaluation and possible etiology. Radiology. 1981;139(1):87-94.

7. Senegor M, Dohrmann GJ, Wollmann RL. Venous angiomas of the posterior fossa should be considered as anomalous venous drainage. Surg Neurol. 1983;19(1):26-32.

8. Peltier J, Toussaint P, Desenclos C, Le Gars D, Deramond H. Cerebral venous angioma of the pons complicated by nonhemorrhagic infarction. Case report. J Neurosurg. 2004;101(4):690-3. doi:10.3171/jns.2004.101.4.0690.

9. Wilms G, Demaerel P, Marchal G, Baert AL, Plets C. Gadolinium-enhanced MR imaging of cerebral venous angiomas with emphasis on their drainage. J Comput Assist Tomogr. 1991;15(2):199-206.

10. Topper R, Jurgens E, Reul J, Thron A. Clinical significance of intracranial developmental venous anomalies. J Neurol Neurosurg Psychiatry. 1999;67(2):234-8.

11. Sarwar M, McCormick WF. Intracerebral venous angioma. Case report and review. Arch Neurol. 1978;35(5):323-5.

12. Abdulrauf SI, Kaynar MY, Awad IA. A comparison of the clinical profile of cavernous malformations with and without associated venous malformations. Neurosurgery. 1999;44(1):41-6; discussion 46-7.

13. Abe M, Asfora WT, DeSalles AA, Kjellberg RN. Cerebellar venous angioma associated with angiographically occult brain stem vascular malformation. Report of two cases. Surg Neurol. 1990;33(6):400-3.

14. Ciricillo SF, Dillon WP, Fink ME, Edwards MS. Progression of multiple cryptic vascular malformations associated with anomalous venous drainage. Case report. J Neurosurg. 1994;81(3):47781. doi:10.3171/jns.1994.81.3.0477.

15. Abe T, Singer RJ, Marks MP, Norbash AM, Crowley RS, Steinberg GK. Coexistence of occult vascular malformations and developmental venous anomalies in the central nervous system: MR evaluation. AJNR Am J Neuroradiol. 1998;19(1):51-7.

16. Chandra PS, Manjari T, Chandramouli BA, Jayakumar PN, Shankar SK. Cavernous-venous malformation of brain stem-report of a case and review of literature. Surg Neurol. 1999;52(3):280-5.

17. Comey $\mathrm{CH}$, Kondziolka D, Yonas H. Regional parenchymal enhancement with mixed cavernous/venous malformations of the brain. Case report. J Neurosurg. 1997;86(1):155-8.

18. Rigamonti D, Spetzler RF. The association of venous and cavernous malformations. Report of four cases and discussion of the pathophysiological, diagnostic, and therapeutic implications. Acta Neurochir (Wien). 1988;92(1-4):100-5.

19. Sasaki O, Tanaka R, Koike T, Koide A, Koizumi T, Ogawa H. Excision of cavernous angioma with preservation of coexisting venous angioma. Case report. J Neurosurg. 1991;75(3):461-4. doi:10.3171/jns.1991.75.3.0461.
20. Scamoni C, Dario A, Basile L. The association of cavernous and venous angioma. Case report and review of the literature. $\mathrm{Br} \mathrm{J}$ Neurosurg. 1997;11(4):346-9.

21. Wilms G, Bleus E, Demaerel P, Marchal G, Plets C, Goffin J, et al. Simultaneous occurrence of developmental venous anomalies and cavernous angiomas. AJNR Am J Neuroradiol. 1994;15(7):124754; discussion 55-7.

22. Van Roost D, Kristof R, Wolf HK, Keller E. Intracerebral capillary telangiectasia and venous malformation: a rare association. Surg Neurol. 1997;48(2):175-83.

23. McCormick PW, Spetzler RF, Johnson PC, Drayer BP. Cerebellar hemorrhage associated with capillary telangiectasia and venous angioma: a case report. Surg Neurol. 1993;39(6):451-7.

24. Arcalis Guaus N, Medrano Martorell S, Cuadrado Blazquez M, Garcia Figueredo D. Capillary telangiectasia and developmental venous anomaly: a rare association. Radiologia. 2011. doi:10.1016/j.rx.2010.11.010.

25. Pozzati E, Marliani AF, Zucchelli M, Foschini MP, Dall'Olio M, Lanzino G. The neurovascular triad: mixed cavernous, capillary, and venous malformations of the brainstem. J Neurosurg. 2007;107(6):1113-9. doi:10.3171/jns-07/12/1113.

26. Bonneville F, Cattin F, Bonneville JF. The juxtaposition of a capillary telangiectasia, cavernous malformation, and developmental venous anomaly in the brainstem of a single patient: case report. Neurosurgery. 2002;51(3):850-1; author reply 1.

27. Tannier C, Pons M, Treil J. Cerebral venous angiomas. 12 personal cases and review of the literature. Rev Neurol (Paris). 1991;147(5):356-63.

28. Rigamonti D, Spetzler RF, Medina M, Rigamonti K, Geckle DS, Pappas C. Cerebral venous malformations. J Neurosurg. 1990;73(4):560-4. doi:10.3171/jns.1990.73.4.0560.

29. McLaughlin MR, Kondziolka D, Flickinger JC, Lunsford S, Lunsford LD. The prospective natural history of cerebral venous malformations. Neurosurgery. 1998;43(2):195-200; discussion 1.

30. Arita $\mathrm{H}$, Kishima $\mathrm{H}$, Hosomi $\mathrm{K}$, Iwaisako $\mathrm{K}$, Hashimoto $\mathrm{N}$, Saitoh Y, et al. Hemifacial spasm caused by intra-axial brainstem cavernous angioma with venous angiomas. Br J Neurosurg. 2012;26(2):281-3. doi:10.3109/02688697.2011.609605.

31. Crecco M, Floris R, Vidiri A, Squillaci E, Sergiacomi GL, Mattioli M, et al. Venous angiomas: plain and contrast-enhanced MRI and MR angiography. Neuroradiology. 1995;37(1):20-4.

32. Herrero A, Martinez-San Millan J, Martinez-Castrillo JC, Ginestal R, Alvarez-Cermeno JC. Developmental venous anomaly of the pons. Neurology. 2001;57(4):744.

33. Konan AV, Raymond J, Bourgouin P, Lesage J, Milot G, Roy D. Cerebellar infarct caused by spontaneous thrombosis of a developmental venous anomaly of the posterior fossa. AJNR Am J Neuroradiol. 1999;20(2):256-8.

34. Naff NJ, Wemmer J, Hoenig-Rigamonti K, Rigamonti DR. A longitudinal study of patients with venous malformations: documentation of a negligible hemorrhage risk and benign natural history. Neurology. 1998;50(6):1709-14.

35. Kuker W, Nacimiento W, Block F, Thron A. Presumed capillary telangiectasia of the pons: MRI and follow-up. Eur Radiol. 2000;10(6):945-50.

36. Huddle DC, Chaloupka JC, Sehgal V. Clinically aggressive diffuse capillary telangiectasia of the brain stem: a clinical radiologic-pathologic case study. AJNR Am J Neuroradiol. 1999;20(9):1674-7.

37. Beukers RJ, Roos YB. Pontine capillary telangiectasia as visualized on MR imaging causing a clinical picture resembling basilar-type migraine: a case report. J Neurol. 2009;256(10):1775-7. doi:.1007/s00415-009-5204-5. 
38. Sehgal V, Delproposto Z, Haacke EM, Tong KA, Wycliffe N, Kido DK, et al. Clinical applications of neuroimaging with susceptibility-weighted imaging. J Magn Reson Imaging. 2005;22(4):43950. doi:10.1002/jmri.20404.

39. Lindquist C, Guo WY, Karlsson B, Steiner L. Radiosurgery for venous angiomas. J Neurosurg. 1993;78(4):531-6. doi:10.3171/ jns.1993.78.4.0531.

40. Meyer B, Stangl AP, Schramm J. Association of venous and true arteriovenous malformation: a rare entity among mixed vascular malformations of the brain. Case report. J Neurosurg. 1995;83(1):141-4. doi:10.3171/jns.1995.83.1.0141.

41. Biller J, Toffol GJ, Shea JF, Fine M, Azar-Kia B. Cerebellar venous angiomas. A continuing controversy. Arch Neurol. 1985;42(4):367-70.
42. Nishizaki T, Tamaki N, Matsumoto S, Fujita S. Consideration of the operative indications for posterior fossa venous angiomas. Surg Neurol. 1986;25(5):441-5.

43. Buhl R, Hempelmann RG, Stark AM, Mehdorn HM. Therapeutical considerations in patients with intracranial venous angiomas. Eur J Neurol. 2002;9(2):165-9.

44. Partain CL, Guinto FC, Scatliff JH, Limbacher J, Janicki P, Heindel CC. Cerebral venous angioma: correlation of radionuclide brain scan, transmission computed tomography, and angiography. J Nucl Med. 1979;20(11):1166-9. 